\title{
Kinetic nucleation and ions in boreal forest particle formation events
}

\author{
L. Laakso ${ }^{1}$, T. Anttila ${ }^{1,3}$, K. E.J. Lehtinen ${ }^{1}$, P. P. Aalto ${ }^{1}$, M. Kulmala ${ }^{1}$, U. Hõrrak ${ }^{2}$, J. Paatero ${ }^{3}$, M. Hanke , and $^{4}$ \\ F. Arnold ${ }^{4}$ \\ ${ }^{1}$ Department of Physical Sciences, P.O. Box 64, FIN-00014 University of Helsinki, Finland \\ ${ }^{2}$ Institute of Environmental Physics, University of Tartu, 18 Ülikooli Street, Tartu, 50090, Estonia \\ ${ }^{3}$ Finnish Meteorological Institute, Air Quality Research, Sahaajankatu 20E, FIN-00880 Helsinki, Finland \\ ${ }^{4}$ Max-Planck-Institute für Kernphysik (MPI-K), D-6900 Heidelberg, P.O. Box 103980, Germany
}

Received: 13 May 2004 - Published in Atmos. Chem. Phys. Discuss.: 20 July 2004

Revised: 22 November 2004 - Accepted: 23 November 2004 - Published: 30 November 2004

\begin{abstract}
In order to gain a more comprehensive picture on different mechanisms behind atmospheric particle formation, measurement results from QUEST 2-campaign are analyzed with an aid of an aerosol dynamic model. A special emphasis is laid on air ion and charged aerosol dynamics. Model simulations indicate that kinetic nucleation of ammonia and sulphuric acid together with condensation of sulphuric acid and low-volatile organic vapours onto clusters and particles explain basic features of particle formation events as well as ion characteristics. However, an observed excess of negative ions in the diameter range $1.5-3 \mathrm{~nm}$ and overcharge of 3-5 $\mathrm{nm}$ particles demonstrate that ions are also involved in particle formation. These observations can be explained by preferential condensation of sulphuric acid onto negatively charged clusters and particles and/or contribution of ion-induced nucleation on particle formation. According to model simulations, which assume that the nucleation rate is equal to the sulfuric acid collision rate, the relative contribution of ion-based particle formation seems to be smaller than kinetic nucleation of neutral clusters. Conducted model simulations also corroborate the recently-presented hypothesis according to which a large number of so-called thermodynamically stable clusters (TSCs) having a diameter between $1-3 \mathrm{~nm}$ exist in the atmosphere. TSCs were found to grow to observable sizes only under favorable conditions, e.g. when the pre-existing particle concentration was low.
\end{abstract}

Correspondence to: L. Laakso

(lauri.laakso@iki.fi)

\section{Introduction}

A considerable number of field measurements indicate that formation of nanometer-size particles and their growth into climatically relevant sizes take place regularly under various atmospheric conditions (Kulmala et al., 2004c). However, the overall climatic importance of this phenomenon is unclear at present due to uncertainties in the links between these initial steps of particle formation and growth and an ultimate influence of new particles on the radiative balance of the Earth (e.g. Ramanathan et al. (2001)). In a view of these uncertainties, detailed investigations of the mechanisms behind new particle formation is warranted.

Several theories have been put forward to explain nucleation and subsequent growth of stable clusters into detectable sizes. Regarding nucleation, binary nucleation of water and sulphuric acid as well as ternary nucleation involving ammonia as a third compound have been proposed as plausible candidates (Korhonen et al., 1999). The nucleation potential of organic compounds (Gaman et al., 2004; Gao et al., 2001; Bonn and Moortgat, 2003) or combination of sulphuric acid and organics (Zhang et al., 2004) is still an open question. Nucleation of iodine compounds is likely to explain massive particle bursts observed in coastal areas (ODowd et al., 2002; Burkholder et al., 2004). Furthermore, ion-induced nucleation according to which stable clusters are formed on atmospheric ions has also been investigated (Arnold, 1980; Laakso et al., 2002; Harrison and Carslaw, 2003; Wilhelm et al., 2004; Yu and Turco, 2000).

Observed particle growth has been hitherto explained by condensation of various organic and inorganic vapours, heterogeneous reactions and self-coagulation (Kulmala et al., 2000a; Kerminen et al., 1997; Zhang and Wexler, 2002;

(C) 2004 Author(s). This work is licensed under a Creative Commons License. 
Anttila et al., 2003). Any plausible theory, however, must predict sufficiently high growth rates since freshly-nucleated clusters are scavenged away very rapidly by pre-existing particles (Kerminen et al., 2001). In particular, it has been suggested that the presence of electric charges in freshly-formed clusters enhance the uptake of polar molecules such as sulfuric acid, thereby giving a growth advantage to charged clusters over neutral ones (Yu and Turco, 2001; Nadykto and Yu, 2003; Nadykto et al., 2004). Atmospheric ions are thus expected to be involved in both nucleation and growth, but their overall importance to particle formation is an open question at present. This is mainly due to the lack of comprehensive set of field measurement data against which different hypothesis could be tested.

In order to gain a more comprehensive picture on different nucleation and growth mechanisms, this paper analyzes measurement results obtained during QUEST (Quantification of aerosol nucleation in the European boundary layer) campaign carried out in SMEAR II-station (Vesala et al., 1998; Kulmala et al., 2001) during March 2003. Results are interpreted utilizing a box model that covers the appropriate aerosol dynamical processes as well as the charge effects. The principal goals of the study are the following:

(1) To present air ion and charging state measurements,

(2) To assess the importance of air ions on new particle formation taking place in the measurement site,

(3) To compare the measurements and model simulations for the measurement period, and

(4) To investigate the possibility that kinetic nucleation explains the evolution of observed ion size distributions.

The measurements and the applied numerical model are described in Sects. 2 and 3, respectively. The measurement results are discussed in Sect. 4.1 and they are compared with model simulations in Sect. 4.2. Conclusions follow in Sect. 5.

\section{Measurements}

Several different instruments were utilized during the measurement period. The mobility distribution of ions was measured with a Balanced Scanning Mobility Analyzer (BSMA) and neutral particles with a differential mobility particle sizer (DMPS). Ionizing radiation was measured by glass-fibre filters and a scintillation gamma spectrometer (Laakso et al., 2004). In addition, the natural charging state of the particles was measured by a special DMPS setup described in Sect. 2.4. Sulphuric acid was observed by a Chemical Ionization Mass Spectrometer (CI-MS) and ammonia by Diffusion Scrubber Flow Injection Analyzer (DS-FIA).

\subsection{BSMA}

The Balanced Scanning Mobility Analyzer manufactured by Airel Ltd., Estonia, consists of two plain aspiration-type dif- ferential mobility analyzers, one for positive and the other for negative ions (Tammet, 2004). The two aspiration condensers are connected as a balanced bridge circuit that allows continuous variation of the driving voltage and scanning of the mobility distribution of charged clusters and nanoparticles called air ions. A large airflow rate of 44 liters per second helps to suppress the loss of air ions at the inlet of the instrument. The inlet can be closed or opened for ions using a controlled electrostatic filter and the background signal is eliminated making every second scan with a closed inlet. A mobility distribution is calculated according to the results of 9 scans performed during 3 minutes. The electric mobility range of $0.032-3.2 \mathrm{~cm}^{2} \mathrm{~V}^{-1} \mathrm{~s}^{-1}$ is divided into 16 fractions that are equally spaced on a logarithmic scale. The mobility distribution is converted to a size distribution using the algorithm developed by Tammet (1995). The size distribution is divided into 12 size classes that are equally distributed in a logarithmic space and span the diameter range $0.4-6.3 \mathrm{~nm}$. The sampling height was about $1.6 \mathrm{~m}$ above the ground.

\subsection{AIS}

The Air Ion Spectrometer (AIS, manufactured by AIREL Ltd, Estonia) measures the mobility distribution of air ions (naturally charged clusters and aerosol particles) in the range of $0.00075-2.4 \mathrm{~cm}^{2} \mathrm{~V}^{-1} \mathrm{~s}^{-1}$. The spectrometer consists of two identical cylindrical aspiration-type differential mobility analyzers, one for measuring positive ions and the other for negative ions. Each mobility analyzer has 21 collector electrodes provided with individual electrometrical amplifiers for the measuring of electrical current carried by ions of different mobilities. The simultaneous measurements enable the recording of the air ion mobility distribution, which is showing considerable variation in ion concentration and evolution in time. The air sample containing ions (flow rate is $500 \mathrm{~cm}^{3} \mathrm{~s}^{-1}$ ) is sucked into the mobility analyzer through the electronically controlled electrostatic filter (switched on/off). The measurements with a closed inlet for ions are used for the verification of the offset level and noise of electrometrical amplifiers. Both mobility analyzers have a closed loop of clean sheath air. The unipolar charging of aerosol particles in the corona charger and the subsequent removal of charged particles by electrostatic filtration is used to create clean sheath airflow of $1000 \mathrm{~cm}^{3} \mathrm{~s}^{-1}$. The mean mobility distributions of positive and negative air ions and distribution uncertainties are calculated averaging the results of 20 measurements recorded during a 5-minute period. The mobility distribution of ions in the range of $0.00075-2.4 \mathrm{~cm}^{2} \mathrm{~V}^{-1} \mathrm{~s}^{-1}$ is presented by 28 logarithmically uniformly distributed fractions: 12 fractions in the mobility range of $0.075-2.4 \mathrm{~cm}^{2} \mathrm{~V}^{-1} \mathrm{~s}^{-1}$ and 16 fractions (two fractions per electrometrical channel) in the range of 0.00075 $0.075 \mathrm{~cm}^{2} \mathrm{~V}^{-1} \mathrm{~s}^{-1}$. The corresponding diameter ranges of single charged particles calculated according to the algorithm by Tammet (1995) are $0.46-4.6$ and $4.6-55 \mathrm{~nm}$ respectively. 


\subsection{DMPS}

Neutral particles were measured by using the differential mobility particle sizer (DMPS). The system consists of two parallel DMPS devices: the first classifies the particles between 3 and $10 \mathrm{~nm}$ and the second between 10 and $500 \mathrm{~nm}$. Both devices uses a Hauke-type differential mobility analyzer (DMA) (Winklmayr et al., 1991) and a closed loop sheath flow arrangement (Jokinen and Mäkelä, 1997). The first device has a $10.9 \mathrm{~cm}$ long DMA and the second one a $28 \mathrm{~cm}$ long DMA. Before sizing the aerosol is neutralized with a $74 \mathrm{MBq} 2(\mathrm{mCi})$ Krypton- 85 beta source. The particle counter of the 1 st device is TSI model 3025 and the 2 nd is TSI model 3010. The time resolution is $10 \mathrm{~min}$. The sampling height was about $2 \mathrm{~m}$ above the ground.

\subsection{Charging state measurements}

A fraction of aerosol particles in the atmosphere is always charged. The particle charge distribution is determined by the ion concentration and the particle size distribution (Wiedensohler, 1990). In stationary conditions, charges are in equilibrium with its electrical environment. However, if the system changes, it takes some time until a new equilibrium is reached. In the DMPS-setup, aerosol particles are led through a charger which, due to its high ion concentration, balances the charge distribution. If, for example, particles have less charges than equilibrium requires, some more particles are charged. On the other hand, if there are too many charges, ions of opposite polarity discharge a fraction of the particles.

In our studies the natural charging state of the particles having a diameter between $3-5 \mathrm{~nm}$ was measured with a special DMPS setup. There were two similar inlets, one with a neutralizer (see Sect. 2.3), the other without a neutralizer (a dummy-one). The DMPS-system switched between these two inlets every 75 seconds. When the concentration measured without the charger was divided by the corresponding charged particle concentration, the natural charging state of the aerosol was obtained. If the value is equal to one, aerosol particles are in a charge equilibrium, whereas values less than one represent undercharged particles and values larger than one indicate overcharge of the particles. The system was calibrated with $4 \mathrm{~nm}$ ammonium sulphate particles which were measured through both inlets. There were 33\% more losses in the neutralizer compared to the dummy inlet and therefore the concentrations measured through charger were corrected by a factor of 1.5 .

\subsection{Gaseous sulphuric acid measurements}

Gaseous sulphuric acid (GSA) was measured by a chemical ionization mass spectrometer apparatus (CI-MS) built by MPI-K Heidelberg. The instrument is essentially the same as the one used for measurements of atmospheric $\mathrm{OH}, \mathrm{HO}_{2}$ and $\mathrm{RO}_{2}$ radicals except for the chemical conversion parts (Hanke et al., 2002). In brief, the CI-MS used in QUEST 2 consists of four major elements including an ion trap mass spectrometer, a flow reactor, an ion source and a GSA-source used for calibration. Atmospheric air at ambient atmospheric pressure is passed through the flow reactor. Simultaneously, reagent ions of the type $\mathrm{NO}_{3}-\left(\mathrm{HNO}_{3}\right)_{n}$ (with $n$ being mostly 1) are produced in the ion source and lead to the flow reactor. There these ions undergo ion-molecule reactions of the type $\mathrm{NO}_{3}-\left(\mathrm{HNO}_{3}\right)_{n}+\mathrm{H}_{2} \mathrm{SO}_{4} \rightarrow \mathrm{HSO}_{4}-\left(\mathrm{HNO}_{3}\right)_{n}+\mathrm{HNO}_{3}$ the rate coefficients of which are close to the ion-molecule collision rate coefficients. The abundance ratio of product and reagent ions is measured using the mass spectrometer. This ion abundance ratio is the base for the determination of the sulphuric acid concentration in the flow reactor. The latter is typically only about $50 \%$ of the ambient atmospheric GSAconcentration due to sulphuric acid losses to the walls of the sampling line and the flow reactor. In order to quantify these sulphuric acid losses a sulphuric acid source is used for careful calibrations. Also carefully determined is the sulphuric acid background signal of the CI-MS-instrument which dictates the GSA-detection limit. During QUEST 2 the GSAdetection limit was as low as about $1 \times 10^{5} \mathrm{~cm}^{-3}$ corresponding to an atmospheric mole fraction of $4 \times 10^{-15}$ or ( $4 \mathrm{ppq}$ ). The time-resolution of the GSA-measurements was below $1 \mathrm{~s}$. The sulphuric acid concentrations were, however, integrated over $60 \mathrm{~s}$ to reduce the statistical error. The absolute uncertainty of the measured GSA-concentration is plus or minus $30 \%$. A paper addressing the CI-MS used and the GSA-measurements made during the QUEST 2-campaign in detail is in preparation (Scholz et al., 2004 ${ }^{1}$ ).

\section{Model description}

A modified version of the model AEROION (Laakso et al., 2002) is applied here in simulating the time evolution of neutral as well as charged clusters and particles. The processes covered by the model are nucleation, coagulation, condensation of sulphuric acid and a low-volatile organic vapour. The effects of charges on these processes are taken into account comprehensively. The model is expressed schematically in Fig. 1.

The model distributes neutral particles into 52 size sections which span the radius range from around $0.3 \mathrm{~nm}$ (radius of one sulphuric acid molecule) to $1000 \mathrm{~nm}$. Each size bin is also divided to 3 charge bins, $-1,0$ and +1 elementary charges. Because the chemical composition of the cluster ions may differ from the composition of the neutral clusters and particles, two additional sections are reserved for negative and positive cluster ions. All particles are assumed to

\footnotetext{
${ }^{1}$ Scholz, S., Hanke, M., Ücker, J., and Arnold, F.: Gaseous Sulfuric Acid Measurements made in the boreal Atmosphere during the QUEST 2 campaign, paper in preparation, 2004.
} 


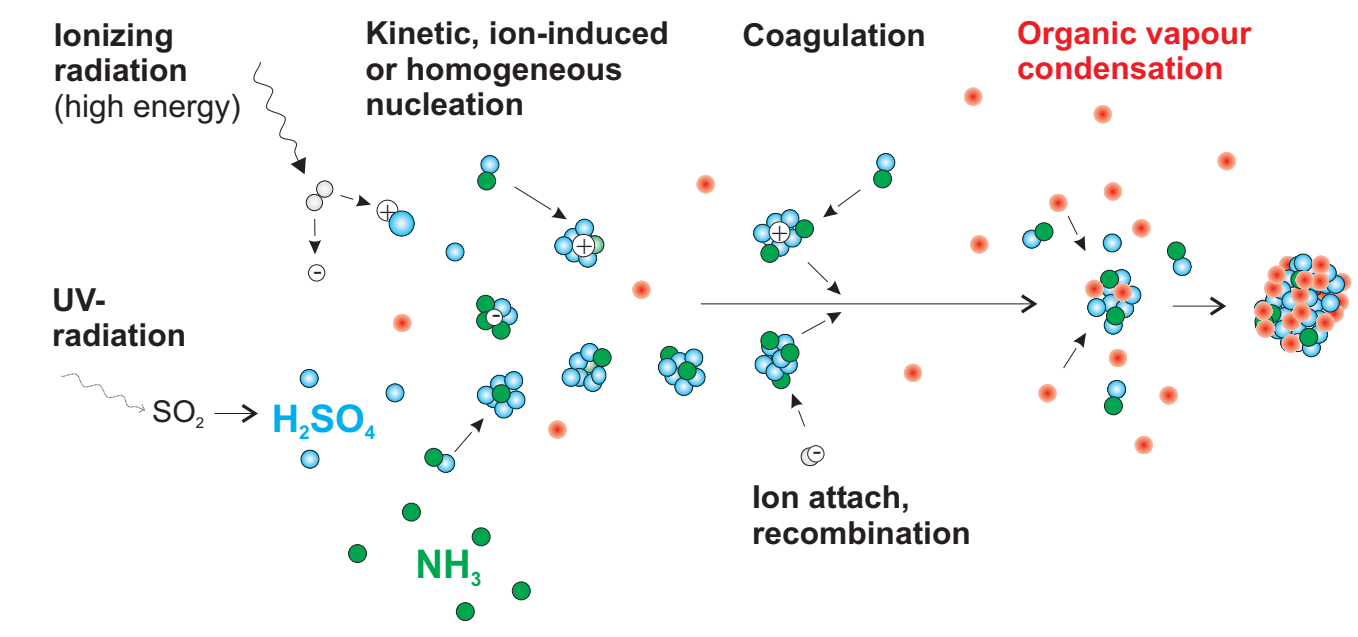

Molecules

Cluster ions and

Observable particles neutral clusters

Particle size increases, time increases

Fig. 1. Schematic picture of the aerosol-ion model.

consist of water, sulphate, ammonium and an organic compound. For particles larger than $40 \mathrm{~nm}$ in diameter the model utilizes measured size distributions. These particles are assumed to be in a charge balance which is determined from the properties of the small ions. In practice, this leads to slightly more negative $(52.5 \%)$ than positive particles $(47.5 \%)$ in the diameter range above $40 \mathrm{~nm}$. However, this assumption does not have a significant effect on the results.

The ion production rate and temperature were taken from the measurements and the particle water uptake was calculated similarly as in the original AEROION model using average measured RH.

Nucleation. A previous analysis of the measurement data indicates that nucleation taking place in the measurement site is limited by the gas-phase kinetics rather than the thermodynamics of ammonia-water-sulphuric acid system (Kulmala et al., 2000b; Kulmala, 2003). Ammonia is assumed to stabilize the clusters (Korhonen et al., 1999; Lee et al., 2003) and therefore the nucleation rate is determined by the coagulation rate of ammonium bisulphate clusters. Since the gasphase concentration of ammonia is clearly higher than that of sulphuric acid (Finlayson-Pitts and Pitts, 2000), it is reasonable to assume that the formation rate of ammonium bisulphate clusters is limited by that of sulphuric acid molecules (Vehkamäki et al., 2004). Accordingly, we assume that the collisions of clusters containing one sulfuric acid molecule result in stable particles, thus the nucleation rate is calculated using the following equation:

$J=0.5 K C^{2}$
Here $J$ is the nucleation rate, $K$ is the coagulation coefficient between ammonium bisulphate clusters and $C$ is the gas-phase concentration of sulphuric acid. Coagulation kernel $K$ is obtained from Fuchs coagulation theory.

We have assumed in this study that ammonia is a stabilizing compound in kinetic nucleation. However, it is possible that in stead of ammonia, sulphuric acid is stabilized by some other compound like some organic vapours having sufficiently high concentration levels in the atmosphere (Zhang et al., 2004). If the stabilizing agent is different from ammonia, the results may slightly change in numbers, but the qualitative conclusions remain the same. In any case, the used expression for nucleation is an upper limit of possible nucleation rates. If the true rate is smaller, the relative importance of ion induced nucleation would increase resulting in higher concentrations of $1.5-3 \mathrm{~nm}$ ions than observed.

Coagulation. Coagulation is treated similarly as in the model AEROION (Laakso et al., 2002), except that the general transition regime coagulation coefficients of Fuchs is applied in determining the coagulation rates (Marlow, 1980). The calculated coagulation coefficients are shown in Fig. 2.

Because a general theory for the calculation of charged cluster coagulation in the kinetic regime is not available, we have repeated our calculations with different approximations (Fig. 2). The first set of calculations is based on Fuchs' general equation in which the coagulation coefficients are corrected with free molecular enhancement factors (blue curves). However, since in the small particle limit the theory is not able to reproduce ion-ion recombination coefficients 


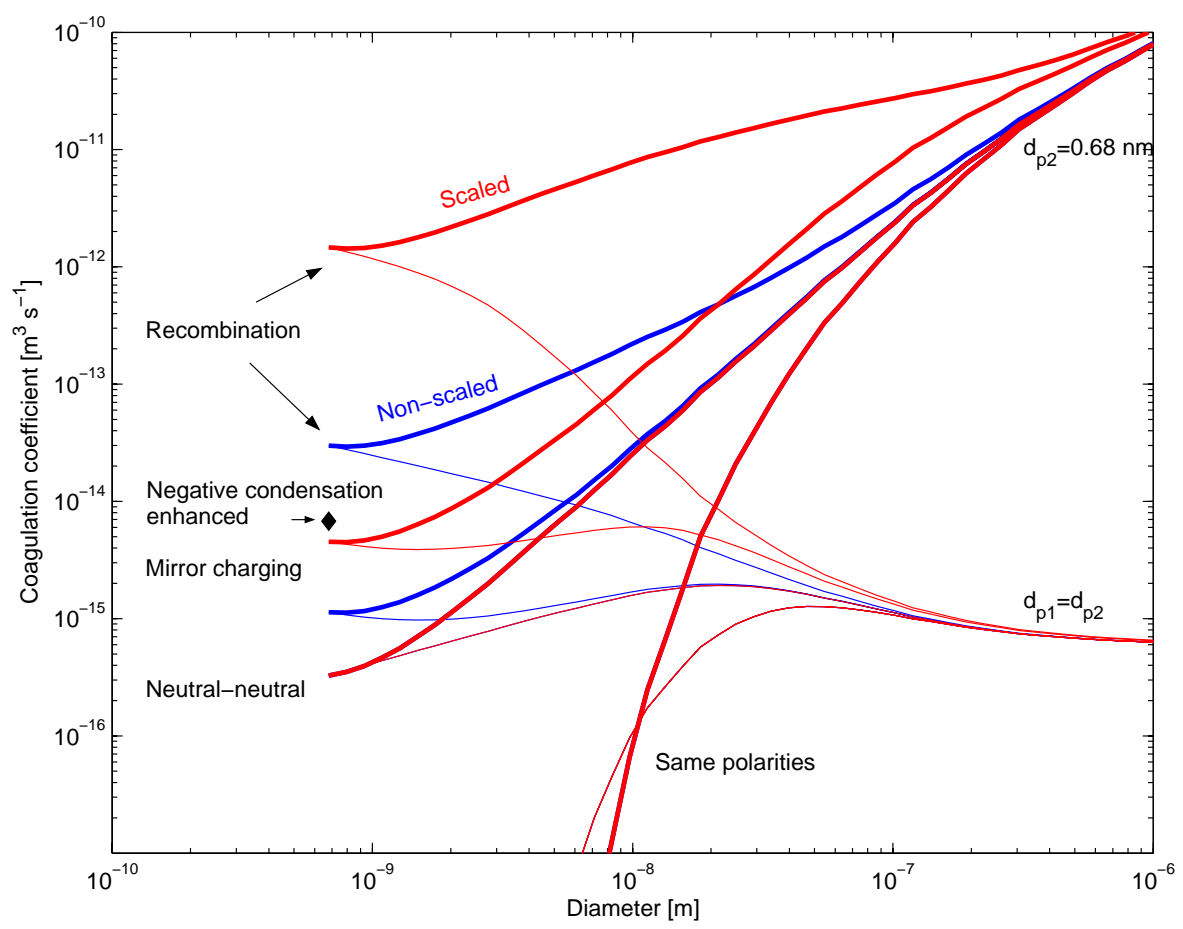

Fig. 2. Coagulation coefficients. Non-scaled coagulation coefficients result from Fuchs generalized theory whereas scaled coagulation coefficients are forced to reach ion-ion recombination and ion-neutral reaction coefficients.

or ion-neutral reaction rates, we also scaled the enhancement factor so that coefficients reach these measured values at molecular size (red curves).

In addition, the value for enhanced sulphuric acid condensation rate is shown. The two sets of curves represent coagulation coefficients between equally sized particles and between a single molecule $\left(\mathrm{d}_{p}=0.68 \mathrm{~nm}\right)$ and a particle of certain size $\left(\mathrm{d}_{p}\right)$.

Ion-aerosol attachment coefficients are calculated based on Fuchs' theory (Fuchs, 1964) as in the earlier version of the model. In some calculations the two ion classes were replaced with charged clusters consisting of a single pair of sulphuric acid and ammonia molecules. The aim was to investigate the effect of chemical composition of the ions to the system. We assumed the average measured properties both for positive and negative cluster ions, $1.4 \times 10^{-4} \mathrm{~cm}^{2} \mathrm{~V}^{-1} \mathrm{~s}^{-1}$ and $1.6 \times 10^{-4} \mathrm{~cm}^{2} \mathrm{~V}^{-1} \mathrm{~s}^{-1}$, respectively. These properties were taken from the BSMA-measurements (vide infra).

Condensation. The condensation of ammonia and sulphuric acid is treated as coagulation between molecules and particles. Ammonia is assumed to condense simultaneously with sulphuric acid so that inorganic salt present in clusters and particles is effectively ammonium bisulphate. The gasphase concentration of sulphuric acid was taken from the measurements.

Preliminary model calculations indicated that the observed particle formation and growth rates can not be produced un- less low-volatile organic vapours are assumed to condense onto clusters and particles. Therefore condensation of a lowvolatile organic vapour was also included into the model.

The mass transfer of the organic vapour between the gas phase and particles is simulated using a version of the condensation equation of Fuchs and Sutugin (1971) which takes into account mirror Coulomb interactions (Lushnikov and Kulmala, 2004). The mass accommodation coefficient of the organic vapour is assumed unity. The condensational flux is driven by the difference $\left(\mathrm{C}_{o s}-\mathrm{C}_{o s, e q}\right)$, where $\mathrm{C}_{o s}$ is the gas-phase concentration of the organic vapour and $\mathrm{C}_{o s, e q}$ its saturation vapour concentration over the cluster or particle surface. Here the model developed by Kulmala et al. (2004a) is applied in calculating $\mathrm{C}_{o s, e q}$. According to the applied model, condensation of low-volatile organic vapours onto nanometer-size clusters is analogous to cloud droplet formation described by the traditional Köhler theory: the clusters "activate" with respect to a low-volatile organic vapour after they have reached a certain threshold size $d_{\text {crit }}$. In order to save computing time, the activation process is treated here assuming that the organic vapour does not condense onto clusters having a diameter below $d_{\text {crit }}$, whereas it is able to condense without any thermodynamic barrier onto clusters and particles above this size, i.e. $\mathrm{C}_{o s, e q}$ is equal to the zero above the surfaces of activated clusters and particles. Based on detailed thermodynamic calculations, the following equation 


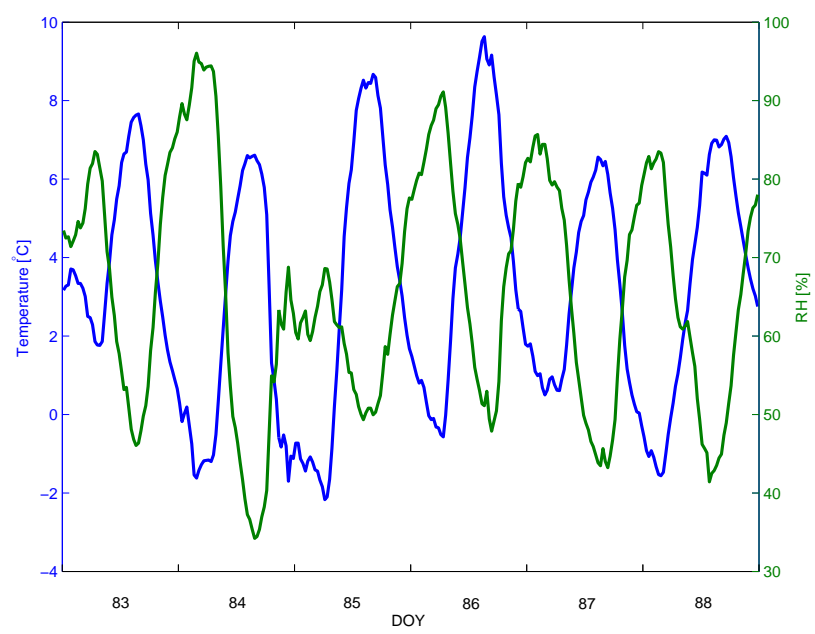

Fig. 3. Temperature and relative humidity measured during the QUEST 2-campaign at SMEAR II-station.

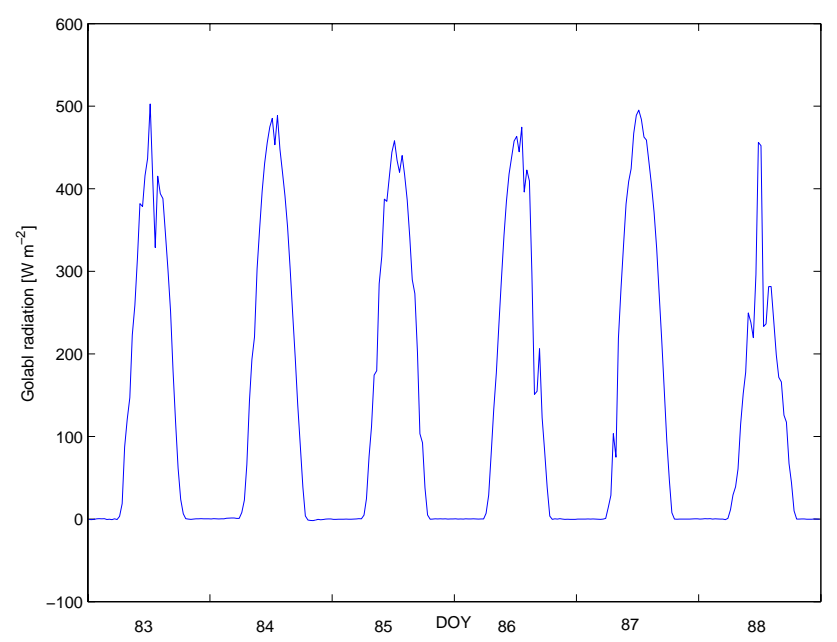

Fig. 4. Global radiation measured during the QUEST 2-campaign at SMEAR II-station.

for $d_{\text {crit }}$ was derived (Kerminen et al., 2004):

$d_{\text {crit }}=\frac{a+b \times T+c \times \ln \left(S_{o s}\right)}{1+d \times T+e \times \ln \left(S_{o s}\right)}$

Here $d_{\text {crit }}$ is given in nanometers, $\mathrm{a}=6.49, \mathrm{~b}=-0.01556$, $\mathrm{c}=0.039, \mathrm{~d}=-0.02, \mathrm{e}=0.174, S_{\text {os }}$ is the ambient saturation ratio of the organic vapour and $T$ is the temperature. This parameterization was shown to mimic closely activation behaviour predicted by the detailed thermodynamic model (Kerminen et al., 2004). The activation diameter, $d_{\text {crit }}$ has values of approximately $2 \mathrm{~nm}$ under considered conditions.

The gas-phase concentration of the organic vapour was assumed to be constant during each day and during the whole period it varied between $2.9-5.1 \times 10^{7} \mathrm{~cm}^{-3}$ (Kulmala et al., 2004b). Furthermore, the saturation vapour concentration of

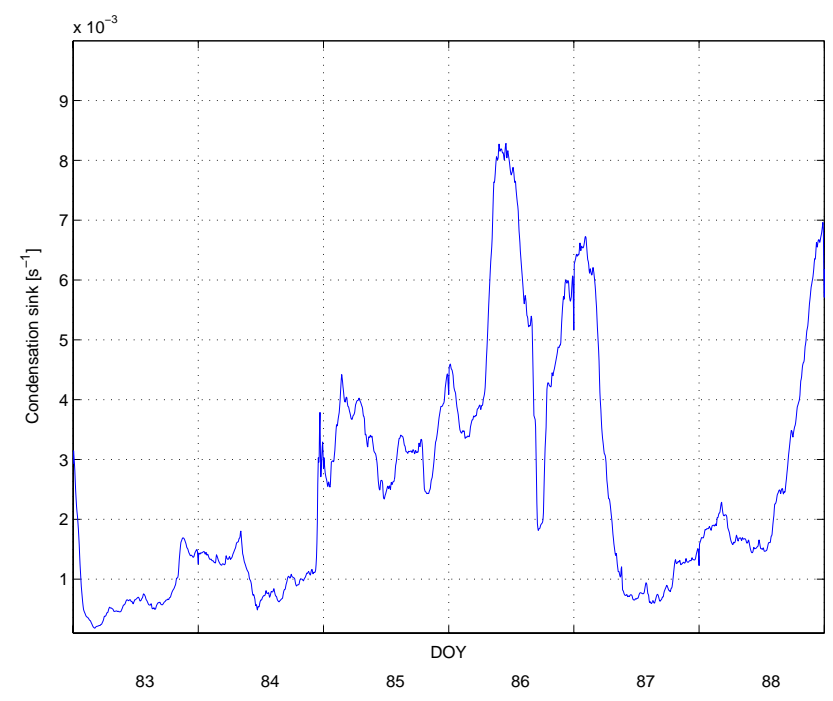

Fig. 5. Condensation sink.

the organic vapour as a pure compound was assumed to be equal to $1 \times 10^{6}$ (Anttila et al., 2003; Kulmala et al., 2004a).

\section{Results}

\subsection{Measurements}

\subsubsection{Meteorology}

Figures 3 and 4 represent the temperature (T), relative humidity (RH) and global radiation during the days $83-88$ (24.3.-29.3.2003). All these quantities exhibit quite similar diurnal variation throughout the whole measurement period. Only during the night 84-85 there were some changes due to the below zero temperatures, which made the air drier than during the other nights. We also looked at satellite pictures for this period (http://www.sat.dundee.ac.uk), all days were clear except day 88 when there were some clouds. This can also be seen from the global radiation measurements.

\subsubsection{DMPS measurements}

The effect of pre-existing particles on new particle formation can be conveniently quantified in terms of condensation sink (CS), i.e. the loss rate of condensing vapours onto preexisting particles. This concept is especially useful since it provides also a measure for the loss rate of freshly-formed clusters/particles due to coagulation (Dal Maso et al., 2002). Similar quantity is the so-called Fuchs surface or Fuchs area.

Figure 5 shows CS during the considered days. It was relatively low during the measurement period except for day 86 and the evening of day 88 .

The particle size distributions measured by DMPS are shown for the considered period in Fig. 6. During days 83, 


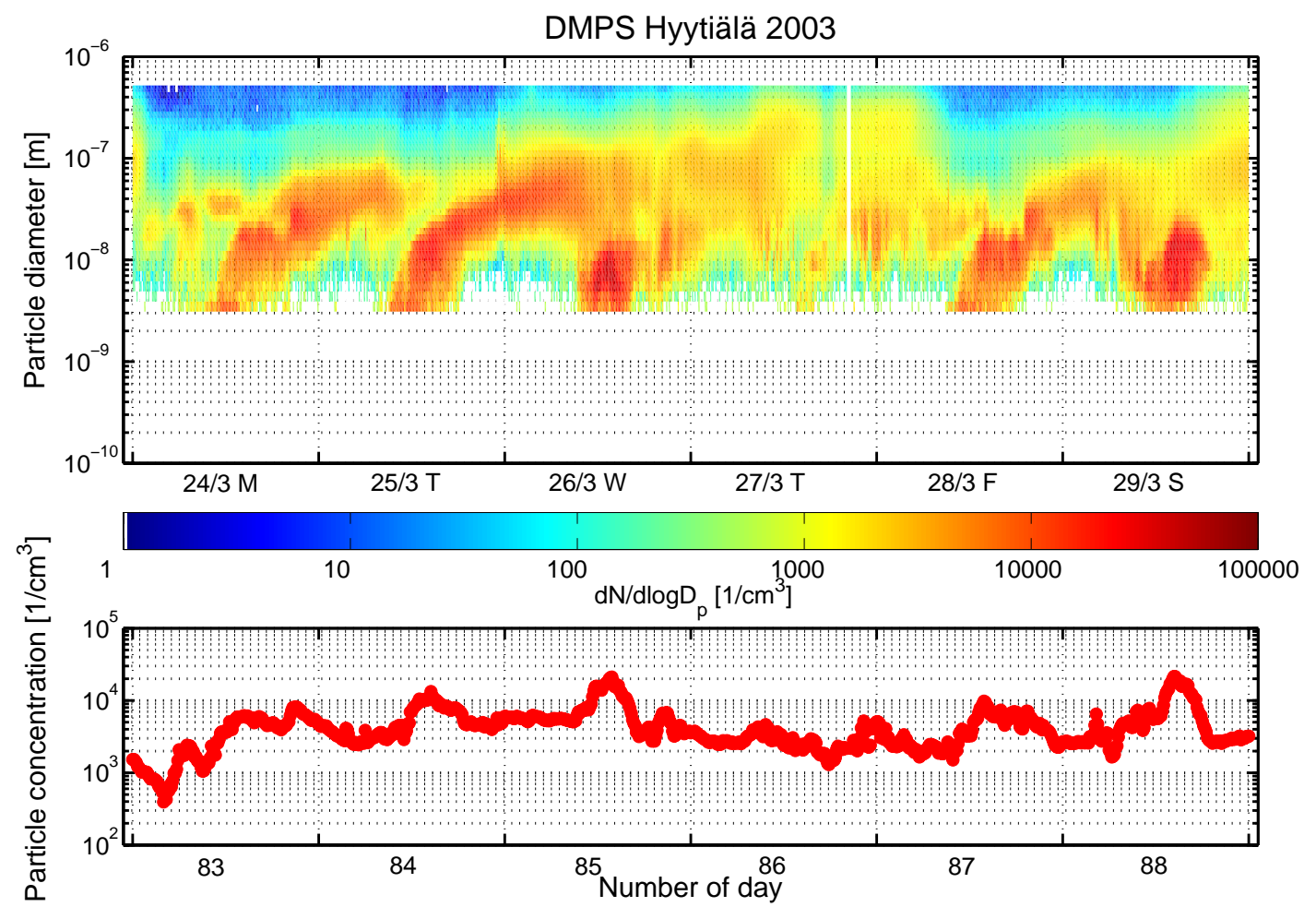

Fig. 6. Particle concentration measured by DMPS during the days 83-89.

$84,85,87$, and 88 apparent particle formation took place whereas during day 86 it was much weaker and lasted for a shorter period.

By comparing DMPS size distributions with the time evolution of CS, it is seen that the value of CS decreases always before pronounced particle formation takes place. In contrast, a large value of CS prevented particle formation in the morning of the day 86 and only a small particle burst took place later during the day. During the afternoon of day 88 , CS starts to increase suppressing growth of the nucleation mode particles. Overall, these observations illustrate the extreme sensitivity of new particle formation to the value of CS (Mönkkönen et al., 2003).

\subsubsection{Ions}

In Figs. 7 and 8, the evolution of the size distribution of negative and positive cluster ions and naturally charged particles (aerosol ions) based on BSMA and AIS measurements are shown, for various days during the period 24-29 March 2003. There are several things that can be seen from the measurements. First, the growing modes consisting of freshlyformed clusters and particles are seen from ion measurements. These modes start growing from cluster ions sizes below $2 \mathrm{~nm}$ in diameter. The growing mode in the size distribution of negative ions is more pronounced (enhanced concentrations) than is the case with positive ions in the size range below $5 \mathrm{~nm}$. This feature (a clear preference of negative ions) has also been found in laboratory experiments (Wilhelm et al., 2004).

The sign preference can be due to an ion-induced particle formation mechanism or sign preference of condensation rate . The latter property could be connected with the geometry of sulphuric acid molecules (Nadykto et al., 2004). The same also applies for condensing organic vapours, but the effect might be smaller because these compounds do not likely condense onto clusters having a diameter below $2 \mathrm{~nm}$ (see the previous section).

The stability of the nanoclusters might also be influenced by a different composition of negative and positive cluster ions (Eisele and Tanner, 1990; Luts and Salm, 1994; Beig and Brasseur, 2000). For example, Lovejoy et al. (2004) observed that negative sulphuric acid ions may grow without any energetic barrier in favourable conditions. According to their study, barrierless negative ion-induced nucleation is predicted if the concentration of sulphuric acid exceeds $10^{7} \mathrm{~cm}^{-3}$ and $\mathrm{RH} 80 \%$ at a temperature of about $270 \mathrm{~K}$. Taking into account the adiabatic cooling in uplifting air in the boundary layer, these values are also met during the studied period.

A purely neutral nucleation tends to create a "gap" between cluster ions and larger charged particles since the charge probability increases with particle size. This is also due to the finite time needed for the particle charging. 

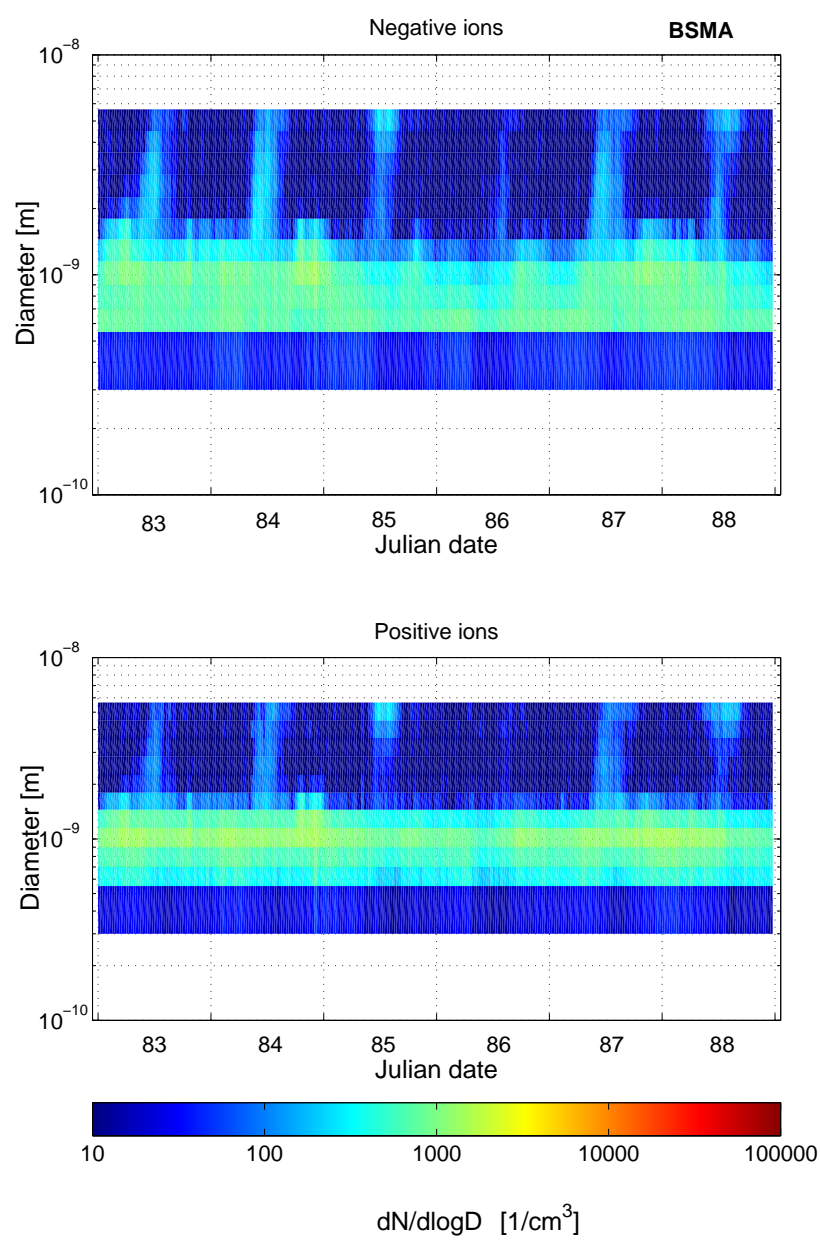

Fig. 7. Ion concentration measured with Balanced Scanning Mobility Analyzer (BSMA) during the days 83-89.

However, this trend is balanced by the decreasing number concentrations with the increasing particle size.

The measurements show that the number concentration of ion clusters in the smallest size class $0.3-0.5 \mathrm{~nm}$ decreases slightly during the particle formation events. This feature is insensitive to the value of CS and is therefore probably connected to particle formation. The size (or mobility) distribution of cluster ions depends on the chemical composition of air (on amount of trace gases) and the concentration of aerosol particles. The latter affects the lifetime of cluster ions in the air, which depends also on the ionization rate, and therefore on the concentration of radioactive substances in the ground and in the air (e.g. radon). Variation of radon concentration due to the mixing causes approximately $10 \%$ difference for the ion production rate between day and night (Laakso et al., 2004). One explanation for the observed decrease is possibly higher concentrations of condensable vapours which grow ions to larger sizes in a shorter time.
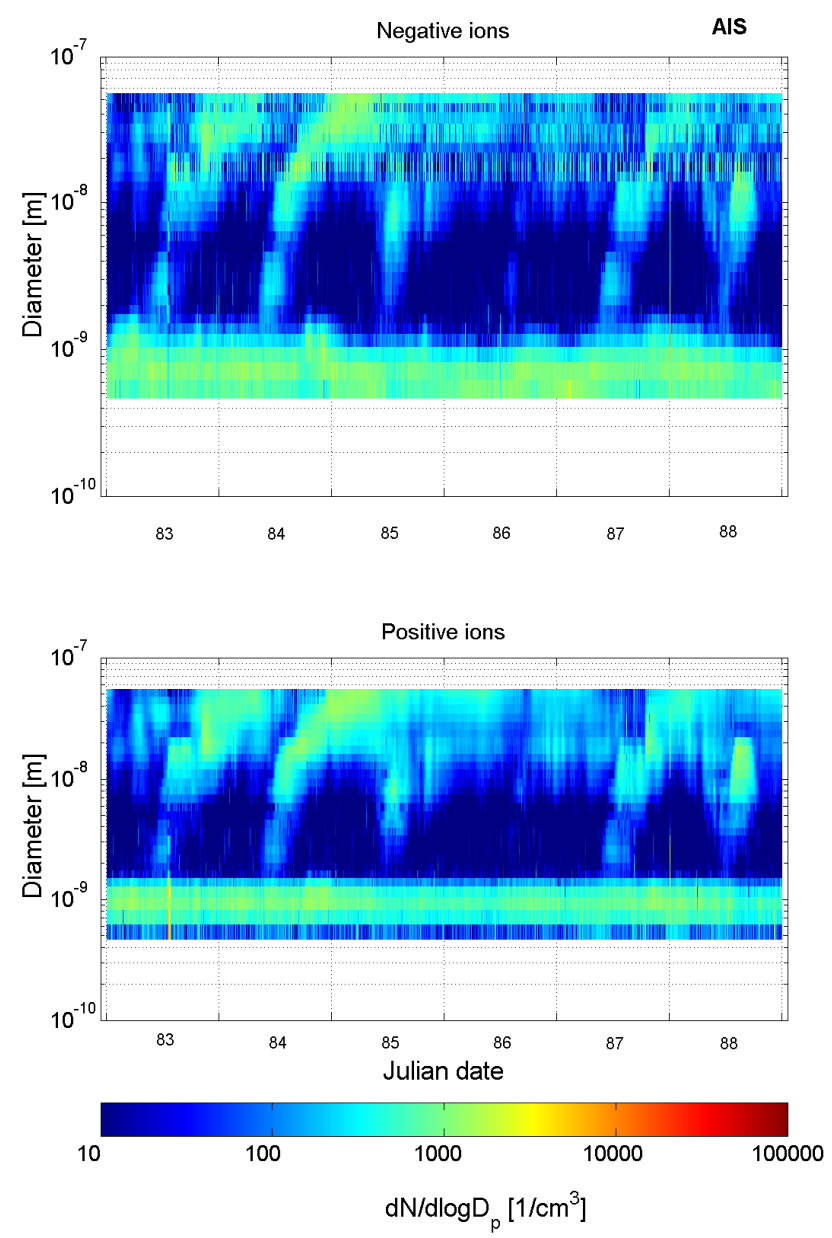

Fig. 8. Ion concentration measured with Air Ion Spectrometer (AIS) during the days $83-89$.

Another interesting observation is that during days 85 and 88 there is a "gap" in the concentrations of ions having sizes $1.5-3 \mathrm{~nm}$ (Figs. 7 and 8). During these days CS is relatively high and and the gap is thus probably linked to the larger scavenging rates of charged clusters. It is also possible that during the days with high CS the nucleation mechanism differs from that of clean days.

\subsubsection{Concentrations of ions and particles and the charging state of 3-5 nm particles}

In Fig. 9 the concentration of ions in certain intervals (from BSMA) and particles are shown. The days with clear particle formation bursts are indicated with red lines at the top of upper panel. In the same panel, the concentration of sulphuric acid is shown, together with the total number concentration measured with DMPS $(3-500 \mathrm{~nm})$ and the concentrations of positive and negative cluster ions.

In the lower panel, the concentrations of positive (red) and negative (blue) ions in size-intervals $1.5-3 \mathrm{~nm}$ and $3-5 \mathrm{~nm}$ 

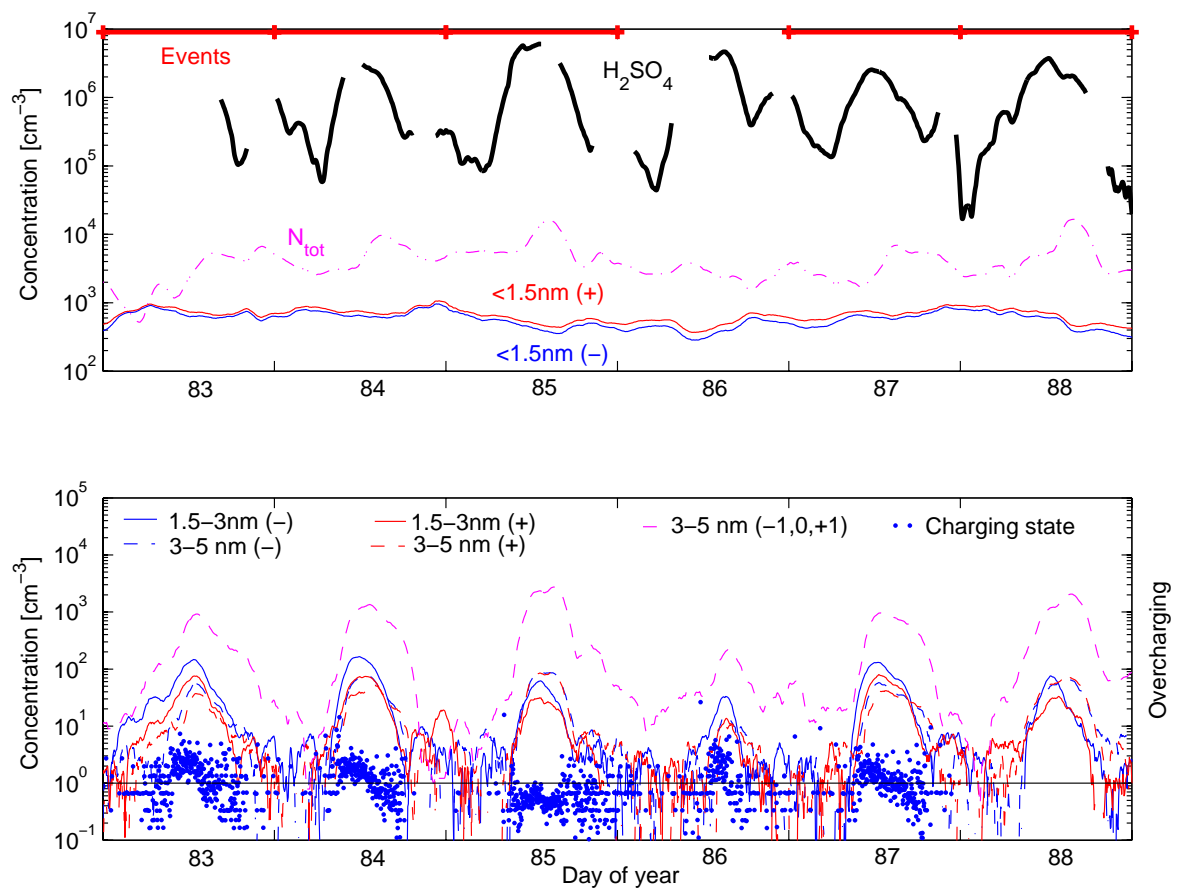

Fig. 9. Particle and ion measurements during the period days $81-88$. In the top panel above shown are the total particle concentration, the number concentrations of ions having a diameter below $<1.5 \mathrm{~nm}$ and the gas-phase concentration of sulphuric acid (curve has gaps). In the bottom panel, blue curves represent negative charges, red curves positive and magenta curves sum over all charges $(-1,0,+1)$. The stars indicate overcharge measurements.

are shown. In addition, the number concentration of particles between $3 \mathrm{~nm}$ and $5 \mathrm{~nm}$ measured with DMPS is given. The charging state of the particles is shown on right axes.

As it can be seen, the concentration of cluster ions was relatively constant during the aerosol formation events. This indicates that ion-induced nucleation can not be the only or the main particle formation mechanism. If we assume that clusters are produced via classical ion-induced nucleation, the nucleation rate depends on the sulphuric acid concentration and the ion production rate. Because the dependence on the sulphuric acid concentration is exponential, the nucleation rate should sometimes reach the ion production rate. This would decrease the cluster ion concentrations notably and increase significantly the concentration of charged particles having sizes $1.5-3 \mathrm{~nm}$, which is in contrast to the observations.

On the other hand, mixing of the air parcels under turbulent conditions may prevent such drastic decrease in the concentrations and change this conclusion (Nilsson et al., 2001).

An alternative explanation for the nearly constant concentration of cluster ions is that the nucleation rate is well below the ionization rate. It was noted that the observed formation rate of $3 \mathrm{~nm}$ size particles in the boreal forest was in the range of $0.001-1 \mathrm{~cm}^{-3} \mathrm{~s}^{-1}$ (Mäkelä et al., 2000), which never exceeded the ion-pair production rate typical for continental areas. The key question is how rapidly cluster ions or critical clusters (e.g. $\mathrm{H}_{2} \mathrm{SO}_{4}$ clusters) grow from initial size up to $3 \mathrm{~nm}$, and how rapid is the coagulational scavenging. Observations (during BIOFOR-campaign, not published) indicated that the ion sink has a minimum before the burst of $3 \mathrm{~nm}$ particles or at the time when the nanoparticle concentration reaches its peak value. So the changes in cluster ion concentration due to ion-induced nucleation can be masked by the changes in the ion sink.

Another interesting feature is that particles were slightly negatively overcharged (indication for ion-induced nucleation) during particle formation events that took place when the value of CS was low. Otherwise particles remained undercharged. Overall, these observations indicate that atmospheric ions are able to influence particle formation taking place at the measurement site.

The third feature worth noting is that the relative concentrations of negative and positive ions in the size range of $3-$ $5 \mathrm{~nm}$ depend on the ion size: negative ions were dominant in the smallest size fractions whereas particles having a diameter above $5 \mathrm{~nm}$ were always equally charged. There are three possible explanations for the first observation: 1) ioninduced nucleation has a negative sign preference (Kusaka et al., 1995; Wilhelm et al., 2004), 2) smaller (negative) ions charge particles more easily due to their higher mobility, and 3 ) the condensation rate onto positive and negative particles is different. Because large differences in the concentration 
and mobility of the negative and positive cluster ions were not observed, the first explanation can not be the dominant one.

In the size range $3-5 \mathrm{~nm}$, the difference in the concentration of negative ions and positive ions was observed to depend on the pre-existing particle concentration. When CS had a high value these concentrations were equal whereas negative ions were otherwise dominant.

\subsection{Model simulations}

The measurement results were analyzed using the developed numerical model. The main goal was to find whether kinetic nucleation of ammonium bisulphate clusters (or sulphuric acid + some unknown compound) together with condensation of sulphuric acid and organic vapours can explain the basic features of the observed particle formation. Regarding ion dynamics, the principal goals were to explain the following two findings:

1. particles were overcharged during particle formation events, and

2. a net unipolar charge existed in the particles with sizes $1.5-3$ and $3-5 \mathrm{~nm}$ in diameter.

The conducted model runs are divided into the following four cases:

1. coagulation coefficients obey enhanced Fuchs coagulation coefficients

2. coagulation coefficients are scaled to reach ion-ion recombination coefficients in the limit of molecular sizes

3. coagulation coefficients obey enhanced Fuchs coagulation coefficients. In addition, the condensation rate of sulphuric acid onto negative particles is 50\% larger than onto the positive particles

4. coagulation coefficients are scaled to reach ion-ion recombination coefficients and the condensation rate of sulphuric acid onto negative particles is 50\% larger than onto the positive particles

Each of these four cases is divided further into three subcases:

a) cluster ions consist of a compound $X$ of which mass and mobility are varied

b) positive ions consist of the compound $\mathrm{X}$ and negative ones ammonium bisulphate

c) both negative and positive ions consist of ammonium bisulphate.

\subsubsection{General features}

New particles were formed in the model runs in equal or higher amounts than observed, the maximum difference being within a factor of three. The timing of particle formation events was also predicted well in all cases. Furthermore, the high CS inhibited particle formation during the day 86 , and particle formation characteristics for polluted days 85 and 88 were different than for the days 83,84 and 87 . However, the charge characteristics and concentrations of nanometer-sized ions were different in different cases.

The particles were always undercharged in cases $1 \mathrm{c}$ and 2c. Assuming different compositions for negative and positive cluster ions, slightly more negative than positive $1.5-$ $3 \mathrm{~nm}$ particles were formed. In addition, the modelled concentrations of the 1.5-3 and 3-5 nm charged particles were of the same order of the magnitude as measured, varying from $100 \mathrm{~cm}^{-3}$ to $800 \mathrm{~cm}^{-3}$. These sets of model runs reproduced also the overcharged/undercharged events. Of all combinations, the measurements were best explained when different condensation rates of sulphuric acid onto negative and positive particles were assumed, i.e. by simulation sets 3) and 4) listed above. The results from these model runs are shown in Figs. 10 and 11 and they can be compared with the corresponding observations shown in Figs. 6-8 and 9.

\subsubsection{Existence of neutral clusters}

The model calculations also suggest that a large number of thermodynamically stable clusters (TSCs) exist below the DMPS detection limit (Fig. 10). The number concentration of clusters having diameter between 1 and $3 \mathrm{~nm}$ varied between $10^{5} \mathrm{~cm}^{-3}$ during the particle formation events and approximately $10 \mathrm{~cm}^{-3}$ in the night. The corresponding variation in charged cluster concentration was $500 \mathrm{~cm}^{-3}$ and $10 \mathrm{~cm}^{-3}$. A small fraction of these charged clusters belong to large cluster ions.

Freshly-formed TSCs are scavenged away rapidly by larger particles and their existence requires a continuous source of new clusters. The model results indicate that a majority of TSCs are neutral. Furthermore, most of TSCs can not be distinguished from the cluster ions because they are not able to reach larger sizes due to the rapid coagulation scavenging. These clusters stabilize the cluster ion distribution and cause the observed fact that the cluster ion concentration is not influenced by particle formation. Initial ions may charge these clusters and, on the other hand, TSCs may form by recombination of ion clusters (Arnold, 1980).

The extremely small size of TSCs makes their atmospheric observation through ion mobility measurements complicated. The best approach for this is perhaps an ion mass spectrometer which would measure ion masses in the size range 50-500 amu (c.f. Eichkorn et al. (2002); Wilhelm et al. (2004)). If one would detect combinations of sulphuric acid and ammonia, the existence of stable ammonium bisulphate 

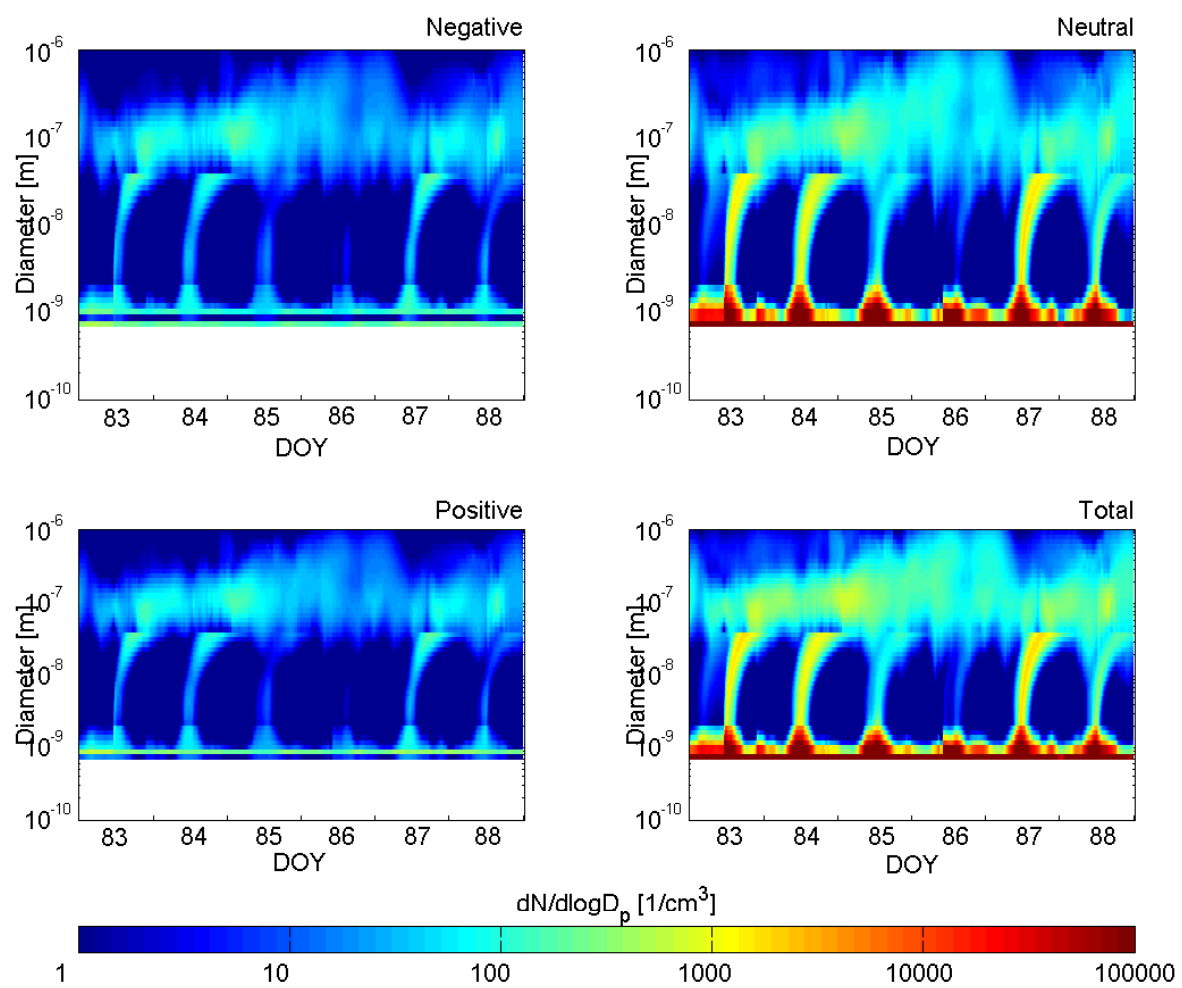

Fig. 10. Charged and neutral particles predicted by model calculations. Ions are assumed to consist 50\% of ammonium bisulphate and 50\% of the unknown compound. Coagulation coefficients are scaled to reach ion-ion recombination coefficient in the small cluster limit. The sulphuric acid condensation rate is enhanced for negative clusters/particles. The measured sulphuric acid concentration used as an input value is also shown for comparison.
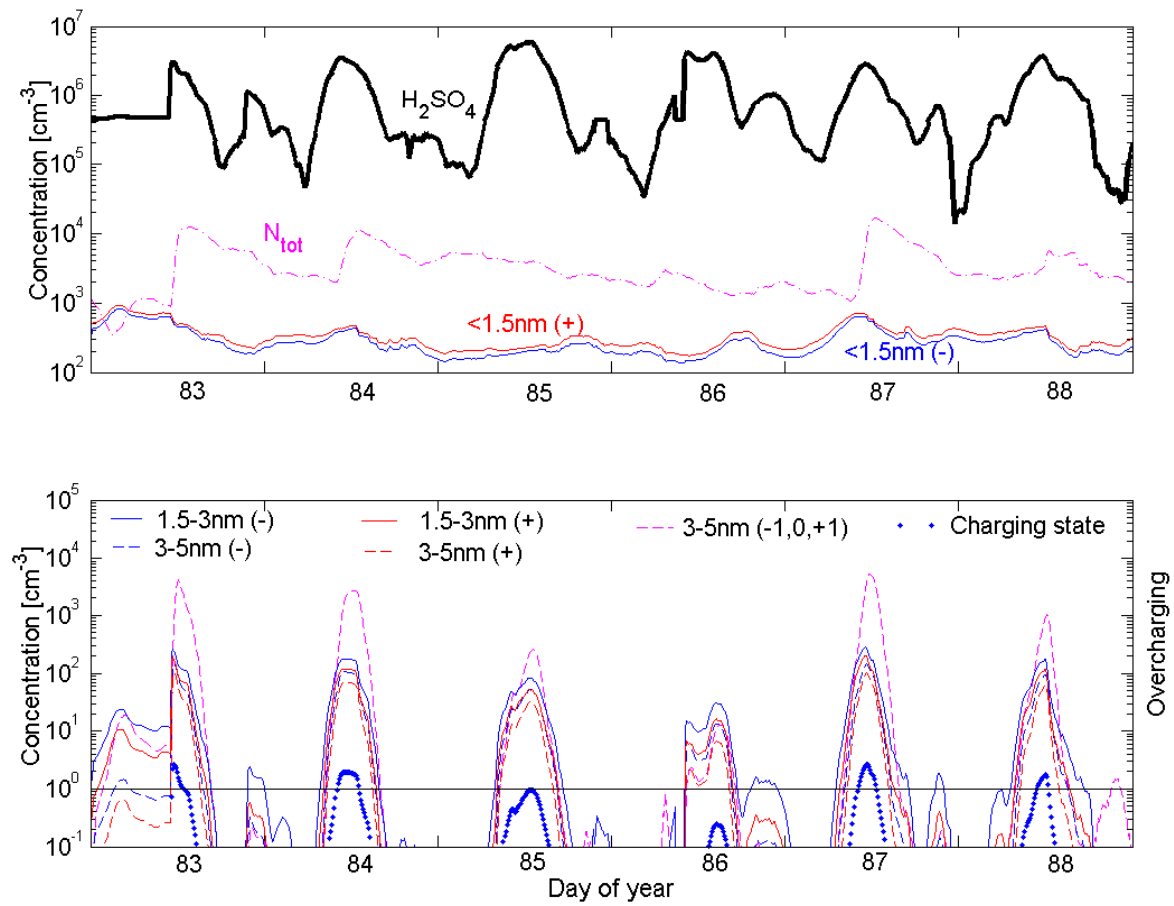

Fig. 11. Fractional concentrations of negative, positive and neutral particles (see Fig. 10 for more details). 
clusters could be inferred. However, e.g. the mass of initial core ions could make the interpretation of the measurements complicated. There are also other possibilities for these measurements based on the properties of traditional condensation particle counters.

\subsubsection{Possibility of binary ion-induced nucleation}

The possibility of binary water-sulphuric acid nucleation was also investigated. The theory for ion-induced binary nucleation predicts that the critical cluster consists of approximately 3-6 sulphuric acid molecules. According to the performed model calculations, however, this leads to significantly larger ion concentrations in the diameter range 1.5-3 $\mathrm{nm}$ than what was observed. In addition, the concentration of cluster ions is significantly decreased which is in contrast with observations. Furthermore, assuming that 1) clusters are produced via ternary ion-induced nucleation and 2) ammonium bisulphate clusters are stable, the number concentration of charged clusters remained many orders of magnitude lower than that of neutral clusters. Thus, even if charged clusters grow faster, the main contribution to over $3 \mathrm{~nm}$ particle concentrations results from neutral clusters.

4.2.4 Role of condensing organic vapours in particle formation

Two sets of model simulations were performed to investigate the sensitivity of the results to the properties of the organic vapour.

First the organic vapour was removed entirely from the system, i.e. its gas-phase concentration was set equal to zero. This lead to such small growth rates that no particles appeared to the diameter range $>3 \mathrm{~nm}$. It can thus be concluded that the observed gas-phase concentrations of sulphuric acid alone cannot explain the particle formation taking place at the measurement site.

In the other case the organic vapour was assumed to condense on all clusters and particles without any thermodynamic barrier, i.e. $\mathrm{C}_{o s, e q}$ was set equal to zero. Because the organic vapour condensed onto all clusters regardless of their size, this resulted in particle concentrations that were more than one order of magnitude higher than the observed ones. This result gives a support to the existence of a certain threshold size below which low-volatile organic vapours do not contribute significantly to the cluster growth.

\section{Conclusions}

In this study, particle formation events observed in a boreal forest site were investigated utilizing measurements and model calculations. Basic features of the measurement results were successfully explained using an aerosol dynamic model that incorporates recent insights into nucleation and condensational growth of freshly-formed clusters. The model runs led to the following conclusions.

Nucleation taking place in the measurement site is probably limited by gas-phase kinetics rather than thermodynamics, i.e. by the coagulation rate of ammonium bisulphate (or some other stabile compound) clusters. Kinetic nucleation produces a large number of mainly neutral stable clusters. Moreover, a clear majority of freshly-formed clusters are predicted to have sizes below $3 \mathrm{~nm}$ in diameter. This finding corroborates the recently presented hypothesis according to which a large number of so-called thermodynamically stable clusters (TSCs) exist below the detection limit of current instrumentation (Kulmala et al., 2000b).

The obtained results are also in agreement with the following picture on cluster and particle growth in boreal forests. First, freshly-formed TSCs are grown by self-coagulation and condensation of sulphuric acid into a threshold size which is around $2 \mathrm{~nm}$ in diameter. After reaching this size, clusters "activate" with respect to low-volatile organic vapour(s) that grow the activated clusters rapidly into detectable sizes via condensation. A distinguishable particle formation ensues only under favourable conditions since TSCs are scavenged away very rapidly by background particles. This highlights the role of a pre-existing particle population in modulating atmospheric particle formation.

The observed excess of negative ions in the diameter range $1.5-3 \mathrm{~nm}$ and the overcharge of $3-5 \mathrm{~nm}$ particles demonstrate that ions are also involved in particle formation. These observations can be explained if sulphuric acid condenses preferably onto negatively charged clusters and particles. Another possibility is the contribution of ion-induced nucleation on particle formation. According to model simulations, which assume that the nucleation rate is determined by sulfuric acid collision rate, the relative importance of ion-based particle formation is probably smaller than kinetic nucleation of neutral clusters and subsequent growth driven by condensation of sulphuric acid and organic vapours.

Edited by: A. Laaksonen

\section{References}

Anttila, T., Kerminen, V.-M., Kulmala, M., Laaksonen, A., and O'Dowd, C.: Modelling the formation of organic particles in the atmosphere, Atmos. Chem. Phys., 4, 1071-1083, 2003, SRef-ID: 1680-7324/acp/2004-4-1071.

Arnold, F.: Multi-Ion complexes in the Stratosphere-Implications for trace gases and aerosol, Nature, 284, 610-611, 1980.

Beig, G. and Brasseur, G.: Model of tropospheric ion composition: A first attempt, J. Geophys. Res., 105, 22 671-22 684, 2000.

Bonn, B. and Moortgat, G.: Sesquiterpene ozonolysis: Origin of atmospheric new particle formation from biogenic hydrocarbons, Geophys. Res. Lett., 30, 1585-1588, 2003.

Burkholder, J. B., Lovejoy, E. R., Ravishankara, A. R., and Curtius, J.: Laboratory studies of the homogeneous nucleation of iodine 
oxides, Atmos. Chem. Phys., 4, 19-34, 2004,

\section{SRef-ID: 1680-7324/acp/2004-4-19.}

Dal Maso, M., Kulmala, M., Lehtinen, K., Mäkelä, J., Aalto, P., and O'Dowd, C.: Condensation and coagulation sinks and formation of nucleation mode particles in coastal and boreal forest boundary layers, J. Geophys. Res., 107, doi:10.1029/2001JD001 053, 2002.

Eichkorn, S., Wilhelm, S., Aufmhoff, H., Wohlfrom, K., and Arnold, F.: Cosmic ray-induced aerosol formation: First observational evidence from aircraft-based ion mass spectrometer measurements in the upper troposphere, Geophys. Res. Lett., 29 (14), doi:10.1029/2002GL015044, 2002.

Eisele, F. and Tanner, D.: Identification of ions in continental air, J. Geophys. Res., 95, 20 539-20 550, 1990.

Finlayson-Pitts, B. J. and Pitts, J. N.: Chemistry of the Upper and Lower Atmosphere, Academic Press., 2000.

Fuchs, N. A.: The mechanics of Aerosol, Pergamon, New York, 1964.

Fuchs, N. A. and Sutugin, A. G.: High-dispersed aerosols, in: Topics in Current Aerosol Research, edited by: Hidy, G. M. and Brock, J. R., vol. 2, pp. 1-60, Pergamon, Oxford, 1971.

Gaman, A. I., Kulmala, M., Vehkamäki, H., Napari, I., Mircea, M., and Facchini, M. C.: Binary homogeneous nucleation in watersuccinic acid and water-glutaric acid systems, J. Chem. Phys., 120, 282-291, 2004.

Gao, S., Hegg, A., Frick, G., Caffrey, P., Pasternack, L., Cantrell, C., Sullivan, W., Ambrusko, J., Albrechcinski, T., and Kirchstetter, T.: Experimental and modelling studies of secondary organic aerosol formation and some applications to the marine boundary layer, J. Geophys. Res, 106, 27 619-27 634, 2001.

Hanke, M., Uecker, J., Reiner, T., and Arnold, F.: Atmospheric peroxy radicals: ROXMAS, a new mass-spectrometric methodology for speciated measurements of $\mathrm{HO}_{2}$ and Sigma $\mathrm{RO}_{2}$ and first results, Int. J. Mass Spectr., 213, 91-99, 2002.

Harrison, R. and Carslaw, K.: Ion-aerosol cloud processes in the lower atmosphere, Rev. Geophys., 41, doi:10.1029/2002RG000 114, 2003.

Jokinen, V. and Mäkelä, J. M.: Closed loop arrangement with critical orifice for DMA sheath/excess flow system, J. Aerosol Sci., 28, 643-648, 1997.

Kerminen, V.-M., Wexler, A. S., and Potukuchi, S.: Growth of freshly nucleated particles in the troposphere: roles of $\mathrm{NH}_{3}$, $\mathrm{H}_{2} \mathrm{SO}_{4}, \mathrm{HNO}_{3}$, and $\mathrm{HCl}$, J. Geophys. Res., 102, 3715-3724, 1997.

Kerminen, V. M., Pirjola, L., and Kulmala, M.: How signifigantly does coagulation scavening limit atmospheric particle production?, J. Geophys. Res., 106, 24 119-24 125, 2001.

Kerminen, V.-M., Anttila, T., Lehtinen, K. E. J., and Kulmala, M.: Parameterization for atmospheric new-particle formation: application to a system involving sulfuric acid and condensable watersoluble organic vapors, Aerosol Sci. Tech., accepted, 2004.

Korhonen, P., Kulmala, M., Laaksonen, A., Viisanen, Y., McGraw, R., and Seinfeld, J.: Ternary nucleation of $\mathrm{H}_{2} \mathrm{SO}_{4}, \mathrm{NH}_{3}$ and $\mathrm{H}_{2} \mathrm{O}$ in the atmosphere, J. Geophys. Res., 104, 26 349-26353, 1999.

Kulmala, M.: How particles nucleate and grow, Science, 302, 10001001, 2003.

Kulmala, M., Korhonen, P., Laakso, L., and Pirjola, L.: Nucleation in boreal forest boundary layer, Environ. Chem. Physics, 22, 4653, 2000a.
Kulmala, M., Pirjola, L., and Mäkelä, J. M.: Stable sulphate clusters as a source of new atmospheric particles, Nature, 404, 66-69, 2000 b.

Kulmala, M., Hämeri, K., Aalto, P., Mäkelä, J., Pirjola, L., Nilsson, E. D., Buzorius, G., Rannik, Ü., Dal Maso, M., Seidl, W., Hoffmann, T., Jansson, R., Hansson, H.-C., O’Dowd, C., and Viisanen, Y.: Overview of the international project on biogenic aerosol formation in the boreal forest (BIOFOR), Tellus B, 53, 324-343, 2001.

Kulmala, M., Kerminen, V.-M., Anttila, T., Laaksonen, A., and O'Dowd, C. D.: Organic aerosol formation via sulphate cluster activation, J. Geophys. Res., 109, doi:10.1029/2003JD003 961, 2004a.

Kulmala, M., Laakso, L., Lehtinen, K., Riipinen, I., Dal Maso, M., Anttila, T., Hõrrak, U., Vana, M., and Tammet, H.: Initial steps of aerosol growth, Atmos. Chem. Phys., 4, 1680-7375, 2004b.

Kulmala, M., Vehkamäki, H., Petäjä, T., Dal Maso, M., Lauri, A., Kerminen, V.-M., Birmili, W., and McMurry, P.: Formation and growth rates of ultrafine atmospheric particles: a review of observations, J. Aerosol Sci., 35, 143-176, 2004c.

Kusaka, I., Wang, Z.-G., and Seinfeld, J. H.: Ion-induced nucleation, II, Polarizable multipolar molecules, J. Chem. Phys., 103, 8993-9009, 1995.

Laakso, L., Mäkelä, J., Pirjola, L., and Kulmala, M.: Model studies on ion-induced nucleation in the atmosphere, J. Geophys. Res., 107, 4427, doi:10.1029/2002JD, 2002.

Laakso, L., Hõrrak, U., Paatero, J., Petäjä, T., Tammet, H., Joutsensaari, J., Lehtinen, K., and Kulmala, M.: Ion production rate in a boreal forest based on ion, particle and radiation measurements, Atmos. Chem. Phys. Discuss., 4, 1680-7375, 2004.

Lee, S.-H., Reeves, J., Wilson, J., Hunton, D., Viggiano, A., Miller, T., Ballenthin, J., and Lait, L.: Particle Formation by Ion Nucleation in the Upper Troposphere and Lower Stratosphere, Science, 301, 1886-1889, 2003.

Lovejoy, E., Curtius, J., and Froyd, K.: Atmospheric ion-induced nucleation of sulfuric acid and water, J. Geophys. Res., 109, doi:10.1029/2003JD004 460, 2004.

Lushnikov, A. and Kulmala, M.: Charging of aerosol particles in the near free-molecule regime, Europhys. J. D, 29, 345-355, 2004.

Luts, A. and Salm, J.: Chemical composition of small atmospheric ions near the ground, J. Geophys. Res., 99, 10 781-10 785., 1994.

Mäkelä, J. M., Dal Maso, M., Pirjola, L., Keronen, P., Laakso, L., Kulmala, M., and Laaksonen, A.: Charasteristics of the atmospheric particle formation events observed at a boreal forest site in southern Finland, Boreal Environ. Res., 5, 299-313, 2000.

Marlow, W.: Derivation of aerosol collision rates for singular attractive contact potentials, J. Chem. Phys., 73, 6284-6287, 1980.

Mönkkönen, P., Koponen, I. K., Lehtinen, K. E. J. , Uma, R., Srinivasan, D., Hämeri, K., and Kulmala, M.: Death of nucleation and Aitken mode particles: observations at extreme atmospheric conditions and their theoretical explanation, J. Aero. Sci., 35, 6, 781-787, 2004.

Nadykto, A. and Yu, F.: Uptake of neutral polar vapour molecules by charged particles: Enhancement due to dipole-charge interaction, J. Geophys. Res., 108 (D23), doi:10.1029/2003JD003 664, 2003.

Nadykto, A. B., Al Natsheh, A., Yu, F., Mikkelsen, K., and Ruuskanen, J.: Effect of molecular structure and hydration on the uptake of gas-phase sulfuric acid by charged clusters/ultrafine particles, 
Aerosol Sci. Technol., in press, 2004.

Nilsson, E., Rannik, ., Kulmala, M., Buzorius, G., and ODowd, C.: Effects of the continental boundary layer evolution, convection, turbulence and entrainment on aerosol tormation, Tellus, 53B, 441-461, 2001.

ODowd, C. D., Jimenez, J. L., Bahreini, R., Flagan, R. C., Seinfeld, J. H., Hämeri, K., Pirjola, L., Kulmala, M., Jennings, S. G., and Hoffmann, T.: Marine aerosol formation from biogenic iodine emissions, Nature, 417, 632-636, 2002.

Ramanathan, V., Crutzen, P. J., Kiehl, J. T., and Rosenfeld, D.: Aerosol, climate and the hydrological cycle., Science, 294, 2119-2124, 2001.

Tammet, H.: Size and mobility of nanometer particles, clusters and ions, J. Aerosol Sci., 26, 459-475, 1995.

Tammet, H.: Balanced Scanning Mobility Analyzer, 16th International Conference on Nucleation \& Atmospheric Aerosols (ICNAA) in Kyoto, 2004.

Vehkamäki, H., Napari, I., Kulmala, M., and Noppel, M.: Stable ammonium bisulphate clusters in the atmosphere, Phys. Rev. Lett., accepted, 2004.

Vesala, T., Haataja, J., Aalto, P., Altimir, N., Buzorius, G., Garam, E., Hämeri, K., Ilvesniemi, H., Jokinen, V., Keronen, P., Lahti, T., Markkanen, T., Mäkelä, J., Nikinmaa, E., Palmroth, S., and Palv: Long-term field measurements of atmosphere-surface interactions in boreal forest combining forest ecology, micrometeorology, aerosol physics and atmospheric chemistry, Trends in Heat, Mass \& Momentum Transfer, 4, 17-35, 1998.
Wiedensohler, A.: Die bipolare Diffusionsaufladung von Partikeln in chemisch trägen Reinsstgasen, $\mathrm{PhD}$ thesis, Univ. of Duisburg, 1990.

Wilhelm, S., Eichkorn, S., Wiedner, D., Pirjola, L., and Arnold, F.: Ion-induced aerosol formation: new insights from laboratory measurements of mixed cluster ions $\mathrm{HSO}_{4}^{-}\left(\mathrm{H}_{2} \mathrm{SO}_{4}\right)_{a}\left(\mathrm{H}_{2} \mathrm{O}\right)_{w}$ and $\mathrm{H}^{+}\left(\mathrm{H}_{2} \mathrm{SO}_{4}\right)_{a}\left(\mathrm{H}_{2} \mathrm{O}\right)_{w}$, Atmos. Environ., 38, 1735-1744, 2004.

Winklmayr, W., Reischl, G. P., Lindner, A., and Berner, A.: A new electromobility spectrometer for the measurement of aerosol size distributions in the size range from 1 to $1000 \mathrm{~nm}$, J. Aerosol Sci., 22, 289-296, 1991.

Yu, F. and Turco, R. P.: Ultrafine aerosol formation via ionmediated nucleation, Geophys. Res. Lett., 27, 883-886, 2000.

Yu, F. and Turco, R. P.: From molecular clusters to nanoparticles: Role of ambient ionization in tropospheric aerosol formation, J. Geophys. Res., 106, 4797-4814, 2001.

Zhang, K. M. and Wexler, A.: A hypothesis for growth of fresh atmospheric nuclei, J. Geophys. Res., 107, 4577, doi:10.1029/20, 2002.

Zhang, R., Suh, I., Zhao, J., Zhang, D., Fortner, E. C., Tie, X., Molina, L. T., and Molina, M. J.: Atmospheric new particle formation enhanced by organic acids, Science, 304, 1487-1489, 2004. 